\title{
Анодные процессы в условиях химического и электрохимического травления кристаллов кремния в кислых фторидных растворах. Механизм порообразования
}

\author{
(С) В.П. Улин, Н.В. Улин, Ф.Ю. Солдатенков
}

Физико-технический институт им. А.Ф. Иоффе Российской академии наук, 194021 Санкт-Петербург, Россия

E-mail: f.soldatenkov@mail.ioffe.ru

(Получена 6 сентября 2016 г. Принята к печати 26 сентября 2016 г.)

В работе изучено взаимодействие с плавиковой кислотой сильно легированных кристаллов кремния $p$ - и $n$-типа проводимости, протекающее без освещения, в отсутствие и при наличии их контакта с металлами, существенно различающимися величиной работы выхода электронов ( $\mathrm{Ag}$ и $\mathrm{Pd}$ ). Определены зависимости от типа и уровня легирования кристаллов скорости растворения кремния в плавиковой кислоте, содержащей окислители с различными значениями редокс-потенциалов $\left(\mathrm{FeCl}_{3}, \mathrm{~V}_{2} \mathrm{O}_{5}, \mathrm{CrO}_{3}\right)$. Анализ экспериментальных данных позволяет сделать вывод о том, что дырки валентной зоны не являются непосредственными участниками анодных реакций окисления и растворения кремния, а их генерация в кристалле не лимитирует скорость этих процессов. Показано также, что тип химического процесса, приводящего к растворению кремния в HF-содержащих электролитах, и скорости его протекания определяются величиной скачка потенциала, устанавливающегося на межфазной границе полупроводник-электролит. Предложена модель механизма электрохимического порообразования в кристаллах кремния, основанная на представлении о самосогласованных кооперативных реакциях нуклеофильного замещения между хемосорбированными анионами фтора и координационно-насыщенными атомами в приповерхностном слое кристалла. В случае кремния специфической особенностью этих реакций является участие в образовании переходных комплексов вакантных несвязывающих $d^{2} s p^{3}$-орбиталей атомов $\mathrm{Si}$, ассоциируемых с шестикратно вырожденными состояниями, соответствующими $\Delta$-долине зоны проводимости. Согласно предложенной модели, процесс порообразования спонтанно развивается в локальных областях межфазной границы под действием скачка потенциала в адсорбционном слое и осуществляется в результате отделения от кристалла полимерных группировок в виде цепочек $\left(\mathrm{SiF}_{2}\right)_{n}$, что и определяет преимущественное распространение пор вдоль кристаллографических направлений $\langle 100\rangle$. Рассмотрены термодинамические аспекты зародышеобразования пор и влияние на размер и структуру пор величины падения потенциала на межфазной границе, типа проводимости и концентрации свободных носителей заряда в кристалле. Развитые в работе представления позволяют предложить непротиворечивое объяснение экспериментальным фактам, характеризующим процессы травления кремния с различными электрофизическими параметрами в различных условиях, обеспечивающих анодную поляризацию кристаллов в НF-содержащих растворах.

DOI: $10.21883 /$ FTP.2017.04.44340.8393

\section{1. Введение}

Открытое 60 лет назад явление электрохимического порообразования в кристаллах кремния до сих пор остается объектом интенсивных и разносторонних исследований, нашедших отражение в сотнях, если не тысячах публикаций. Тем не менее этот феномен самоорганизующегося дискретного травления кремниевых монокристаллов, проявляющийся только в НF-содержащих растворах под воздействием анодного смещения или в присутствии окислителей, не нашел пока однозначного объяснения.

Любые процессы порообразования в кремнии, независимо от характера и условий их инициирования, типа и уровня легирования исходных кристаллов и структурных особенностей образующегося пористого слоя, объединяются такими общими признаками, как: a) спонтанная локализация химического процесса в дискретных, однородно распределенных областях межфазной границы, включающих как минимум сотни ато- мов решетки травящегося кристалла; б) эффективная валентность атомов кремния, определяемая по соотношению количества атомов, переходящих в раствор в единицу времени, к величине анодного тока, не достигает 4 и близка к 2 в условиях выделения водорода из области протекания анодной реакции. Предложен ряд физических моделей, предлагающих объяснение отдельных аспектов процессов порообразования исходя из представлений о неустойчивости к малым периодическим возмущениям планарной границы раздела кремний-электролит в условиях электрохимического травления $[1,2]$ и локализации анодного тока на вогнутой поверхности дна прорастающих пор вследствие туннельного или лавинного пробоя слоя объемного заряда в полупроводнике или диэлектрическом слое оксидной фазы на его поверхности [3-7]. Химические модели концентрируются на объяснении величины эффективной валентности кремния и механизма выделения водорода, сопровождающего переход в раствор атомов поверхностного слоя кристалла [8-10]. Наиболее признанными 
в настоящее время являются модели, постулирующие необходимость первоначального захвата дырок связями $\mathrm{Si}-\mathrm{H}$, исходно терминирующими поверхность кристалла, что обеспечивает возможность последующей атаки на них анионов фтора с отщеплением протона и эмиссией электрона в зону проводимости. Затем образовавший химическую связь с поверхностью кристалла электроотрицательный атом фтора поляризует ближайшие к нему связи $\mathrm{Si}-\mathrm{Si}$, облегчая диссоциативную адсорбцию на них молекул HF, сопровождающуюся переходом молекулы $\mathrm{SiF}_{4}$ или $\mathrm{SiHF}_{3}$ в раствор и восстановлением исходного состояния гидрированной поверхности. Вариации этого подхода сводятся к вопросу о локализации образования молекулярного водорода - непосредственно на поверхности кристалла (для иллюстрации модели всегда выбирается поверхность (100), терминированная группами $\mathrm{SiH}_{2}$ ) или в объеме электролита при взаимодействии промежуточного продукта $\mathrm{SiHF}_{3}$ с молекулами НF.

Нетрудно, однако, заметить слабые стороны такой интерпретации рассматриваемого процесса. Во-первых, известно, что уровни энергии электронов на связях $\mathrm{Si}-\mathrm{H}$, пассивирующих поверхность кремния и значительно более прочных, чем связи $\mathrm{Si}-\mathrm{Si}$ (70 и 42 ккал/моль соответственно), лежат внутри валентной зоны кремния, что делает вероятность локализации на них дырки многократно меньшей, чем на связях $\mathrm{Si}-\mathrm{Si}$. Во-вторых, предположение об инициировании „всплывающими“ дырками всей цепочки элементарных процессов, приводящих к отделению атомов от решетки, не согласуется с экспериментальным фактом порообразования в сильно легированных кристаллах кремния $n$-типа проводимости (при концентрациях электронов $n>10^{19} \mathrm{~cm}^{-3}$ ), представляющих собой вырожденный полупроводник, поскольку очевидно, что скорость электронно-дырочной рекомбинации должна превышать скорость любого гетерофазного химического процесса. В-третьих, остается неясным фактор, определяющий смену механизмов травления при повышении напряжения поляризации, - от порообразования, в котором кремний проявляет валентность 2, до однородного травления без выделения водорода при валентности, равной 4. Используемая для объяснения этого явления гипотеза о первоначальном электрохимическом образовании оксидного слоя на кремниевой поверхности, анодируемой при высоких плотностях тока в водных растворах HF, с последующим химическим растворением окисла в электролите [3] плохо согласуется с тем, что диссоциативная адсорбция воды на кремнии (хемосорбция анионов $\mathrm{OH}^{-}$) термодинамически значительно менее выгодный процесс, чем диссоциативная адсорбция HF (хемосорбция анионов $\mathrm{F}^{-}$), и в кислых средах способна развиваться лишь при практически полном отсутствии ионов фтора у реакционной поверхности. Известно, например, что окисел на кремнии не образуется в воде уже при концентрации в ней $\mathrm{HF} \sim 10$ ppm. Поэтому по крайней мере для электролитов, содержащих $\mathrm{H}_{2} \mathrm{O}$ и $\mathrm{HF}$ в сопоставимых концентрациях, формирование анодного окисла представляется маловероятным даже в условиях значительного обеднения HF приграничного слоя раствора. Прямым экспериментальным опровержением обсуждаемой гипотезы может служить сплошное травление кремния, без выделения водорода, наблюдавшееся нами в независимости от плотности анодного тока в электролите, представляющем собой продукт завершенной реакции плавиковой кислоты со сверхстехиометрическим количеством аморфной двуокиси кремния $\mathrm{SiO}_{2}$. Наконец, ни одна модель процесса травления кристалла, рассматривающая его как совокупность взаимонезависимых актов отрыва от решетки одиночных атомов, не может объяснить появление входных отверстий пор, вплоть до их микрометровых размеров, непосредственно на исходной поверхности кристалла, минуя (в отсутствие фотовозбуждения) неизбежную в таком случае стадию сплошного травления, предшествующую формированию стационарной системы синхронно прорастающих каналов.

В своем наиболее обстоятельном на сегодняшний день анализе процессов травления кремния во фторидных растворах К. Коласинский $[11,12]$ обходит проблему невозможности непосредственного захвата дырок связями $\mathrm{Si}-\mathrm{H}$ и даже отличающимися по энергии от существующих в объеме связями $\mathrm{Si}-\mathrm{Si}$ внешнего атомного слоя кристалла (back bonds), постулируя существование электростатического взаимодействия между объемными делокализованными состояниями дырок в кристалле, находящихся вблизи поверхности, и сольватированными анионами фтора в растворе. Далее полагается, что в области появления таких межфазных ассоциатов снижается активационный барьер реакции замещения хемосорбированного водорода фтором. Такое утверждение не обосновывается теоретически, и в качестве единственного довода в его пользу приводится экспериментальный факт фотостимуляции травления кремния в плавиковой кислоте. Сразу заметим, что и при этой интерпретации ключевой стадии взаимодействия гидрированной поверхности кремния с HF в рамках используемых представлений не удается объяснить травление сильно легированных кристаллов $n$-типа проводимости.

В сравнительно недавних работах группы Коласинского, посвященных изучению бестокового (electroless) травления кремния в растворах плавиковой кислоты c различными окислителями $\left(\mathrm{V}_{2} \mathrm{O}_{5}, \mathrm{FeCl}_{3}, \mathrm{H}_{2} \mathrm{IrCl}_{6}\right.$, $\mathrm{CeF}_{4}$ ), была проанализирована кинетика формирования пористых слоев в предположении, что инжекция дырок в валентную зону, сопровождающая гетерогенное восстановление окислителя, является в соответствии с утверждаемой ими моделью лимитирующей стадией растворения кремния [13]. Проведенные на основе теории Маркуса оценки констант скорости электронного переноса между полупроводником и окислителем привели к удовлетворительному, по порядку величины, согласию с экспериментальными значениями только для одного окислителя - $\mathrm{VO}_{2}^{+}$. Для остальных же окислителей расхождения составили 2-4 порядка величины. 

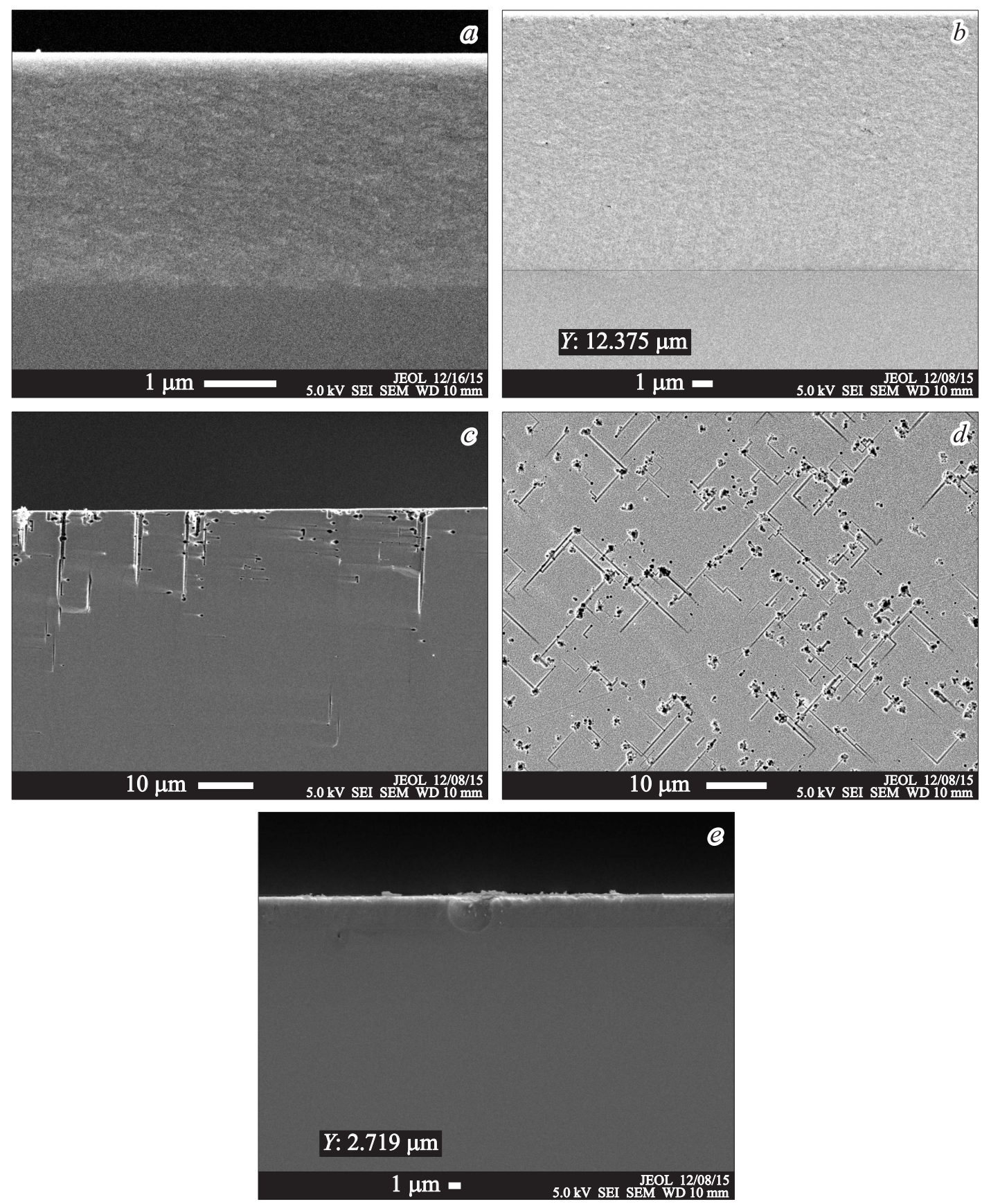

Рис. 1. SEM-изображения пористых слоев, сформировавшихся в результате темновой экспозиции в течение 70 ч в $48 \%$-й $\mathrm{HF}$ при комнатной температуре на пластинах $n^{+}-\mathrm{Si}(100)$, находившихся в контакте со слоями $\mathrm{Ag}(a)$ и $\mathrm{Pd}(b)$, а также без контакта с металлом при $75^{\circ} \mathrm{C}(c-$ скол, $d-$ поверхность $) ; e-$ пористый слой на $p^{+}-\mathrm{Si}(100)$, образовавшийся при комнатной температуре в контакте с Pd.

В настоящей работе мы прежде всего попытались выяснить, действительно ли непосредственное участие дырок валентной зоны необходимо для осуществления травления кремния в растворах HF и обязательно ли генерация их в кристалле является стадией, лимитирующей скорость его растворения в процессах порообразования, а также какими факторами определяется переход от порообразования к сплошному травлению с образованием продуктов полного окисления кремния.
Затем, опираясь на полученные выводы, мы адаптировали для объяснения порообразования в кремнии обоснованную ранее применительно к соединениям $\mathrm{A}^{\mathrm{III}} \mathrm{B}^{\mathrm{V}}$ модель самоорганизующихся кооперативных реакций нуклеофильного замещения между хемосорбированными анионами и координационно-насыщенными атомами приповерхностного слоя решетки кристалла, инициируемых полем скачка потенциала на межфазной границе электролит-полупроводник $[14,15]$. 


\section{2. Влияние типа проводимости и концентрации свободных носителей заряда в кристаллах кремния на скорости их травления в HF-содержащих растворах}

Для ответа на поставленные выше вопросы мы провели вначале несколько простых экспериментов, выдержав в течение 70 ч в плавиковой кислоте (48\%-я HF), при комнатной температуре и без освещения пластины сильно легированного кремния, ориентации (100), n- и $p$-типа проводимости (удельное сопротивление 0.005 и 0.0025 Ом · см соответственно). Обратные стороны пластины были покрыты химически осажденными слоями серебра и палладия. Серебро осаждалось из водного раствора $\mathrm{AgF}$, а палладий - из раствора $\mathrm{PdCl}_{2}$ с внесением в него НF после смачивания обрабатываемой поверхности. Кроме того, такие же пластины кремния, но без нанесения металлического слоя, выдерживались в кислоте те же 70 ч при температуре $\sim 75^{\circ} \mathrm{C}$. При нормальных условиях в течение выбранного времени не наблюдалось заметных проявлений взаимодействия HF с кремнием обоих типов проводимости. Было обнаружено, что без контакта с металлом и в случае контакта кремния с серебром химическое взаимодействие с HF протекало только на пластинах $n$-типа проводимости, поверхности пластин $p$-типа проводимости остались без видимых изменений. На пластинах $\mathrm{Si} p$-типа, контактировавших с палладием, взаимодействие с HF выразилось в образовании пористого слоя с низкой степенью пористости (слабый контраст по отношению к сплошному кристаллу на изображениях, полученных в сканирующем электронном микроскопе (SEM)) и толщинами, в $\sim 5$ раз меньшими, чем в тех же условиях на пластинах $n$-типа проводимости (см. рис. $1, a-e$ ).

Полученные результаты нетрудно объяснить, если учесть, что уровень водородного редокс-потенциала $\left(E_{\mathrm{H}+/ \mathrm{H} 2}\right)$ в кислых растворах соответствует энергиям электронов внутри запрещенной зоны кремния (для $p \mathrm{H} \sim 1, E_{\mathrm{H}+/ \mathrm{H} 2} \sim-4.45$ эВ, энергии краев зоны проводимости $E_{C}(\mathrm{Si})=-4.05$ эВ и валентной зоны $E_{V}(\mathrm{Si})=-5.17$ эВ, см. рис. 2) и, следовательно, для $n-\mathrm{Si}$ установление электрохимического равновесия предполагает транспорт электронов проводимости в раствор с восстановлением водорода на самой кремниевой поверхности или на металлическом противоэлектроде. С появлением положительного заряда на кремнии, так же как и при внешней анодной поляризации, между полупроводником и раствором возникает разность потенциалов, дающая непосредственный вклад в величину теплового эффекта реакций хемосорбции анионов поверхностью кристалла [15]. Это, в свою очередь, ведет к снижению активационных барьеров соответствующих процессов и, в частности, нуклеофильного замещения адсорбированного водорода анионом фтора. Естественно, что повышение температуры ускоряет протекание всех по-

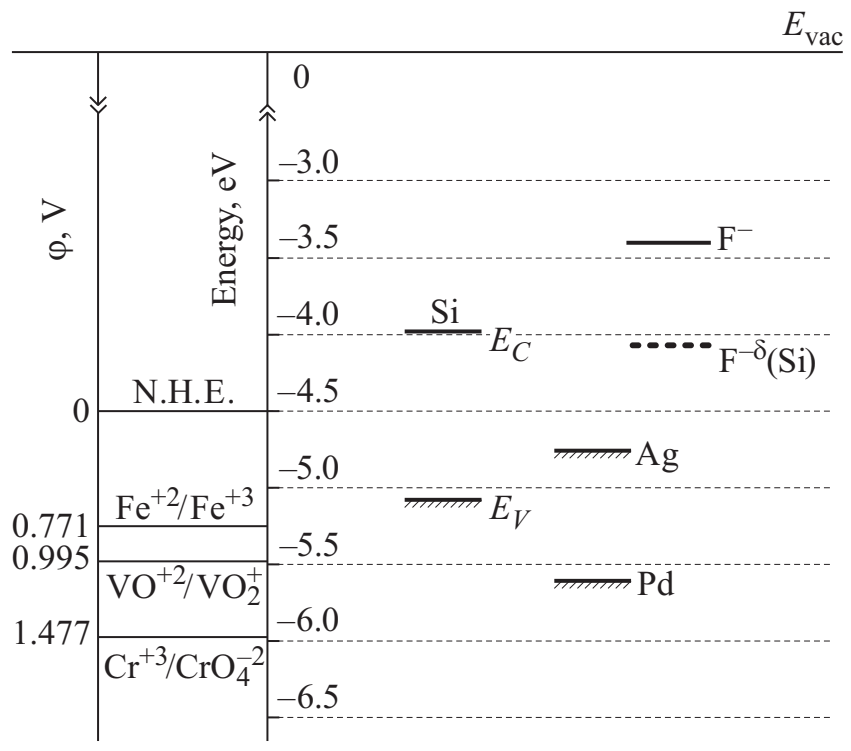

Рис. 2. Взаимное расположение отсчитываемых от уровня энергии электрона в вакууме $\left(E_{\mathrm{vac}}\right)$ краев зоны проводимости $\left(E_{c}\right)$ и валентной зоны $\left(E_{V}\right)$ кремния, уровней Ферми для электронов в $\mathrm{Ag}$ и $\mathrm{Pd}$, потенциала нормального водородного электрода (N.H.Е.) и стандартных значений редокс-потенциалов $(\varphi)$ для систем $\mathrm{Fe}^{+3} / \mathrm{Fe}^{+2}, \mathrm{VO}_{2}^{+} / \mathrm{VO}^{+2}$ и $\mathrm{CrO}_{4}^{-2} / \mathrm{Cr}^{+3}$ в водных растворах, а также положение энергии валентных электронов свободного аниона $\mathrm{F}^{-}$и предполагаемое положение их для адатомов фтора $\mathrm{F}^{-\delta}(\mathrm{Si})$ на поверхности кремния.

тенциально возможных реакций на межфазной границе. Напомним, что наблюдаемая химическая стабильность кремния в плавиковой кислоте при комнатных температурах обусловлена исключительно кинетическими, а не термодинамическими ограничениями. Подтверждением этому может служить сам факт гидридной пассивации кремния в НF, вызываемой обменной реакцией с замещением водородом внешнего атомного слоя кристалла: $-\mathrm{Si}_{n}-\mathrm{Si}-\mathrm{F}_{4-n}+n \mathrm{HF}=\mathrm{SiF}_{4}+(-\mathrm{SiH})_{n}$.

Металлический слой, контактирующий с кремнием, выполняет функцию стока для электронов и области локализации катодного процесса восстановления водорода. Для развития анодного процесса на кремнии принципиальным в данном случае оказывается положение уровня Ферми металла относительно положений краев энергетических зон кремния. Для серебра работа выхода составляет 4.74 эВ, что соответствует положению уровня Ферми металла в запрещенной зоне кремния, тогда как для палладия эта величина равна 5.6 эВ, что ниже потолка валентной зоны кремния (см. рис. 2). Поэтому равновесие между электронными подсистемами палладия и кремния предполагает перенос на металл не только электронов проводимости, но и электронов валентной зоны полупроводника. Это означает, что в ходе установления общего электрохимического равновесия в системе палладий-кремний-〈раствор НF $\rangle$ положительный относительно электролита заряд должен появляться 
и на кристаллах $p$-типа проводимости. Однако величина падения потенциала между кремнием и электролитом, при которой осуществляется анодная реакция, в случае кристаллов $n$-типа проводимости оказывается выше, чем для кристаллов $p$-типа (в пределе на $\sim E_{g} / e, E_{g}-$ ширина запрещенной зоны, т.е. $\sim 1.1 \mathrm{~B})$, что и определяет разницу в скоростях травления и толщинах пористых слоев.

Таким образом, результаты проведенных экспериментов служат прямым доказательством того, что условием начала химического взаимодействия между кремнием и электролитом является не транспорт дырок к поверхности как таковой, а сдвиг потенциала кремния в положительную сторону относительно раствора НF. Поскольку в эксперименте участвовали кристаллы сильно легированного, близкого к вырождению, кремния, уровень Ферми в которых примыкает к разрешенным зонам, возникающее в процессе установления электрохимического равновесия падение потенциала между полупроводником и электролитом практически полностью локализуется в слое Гельмгольца (эффект открепления границ зон вырожденного полупроводника в электролите [16]). Это означает, что наблюдаемое спонтанное травление кремния, протекающее как порообразование, является прямым следствием возрастания скачка потенциала непосредственно на межфазной границе. В рамках приведенной интерпретации рассматриваемых явлений нетрудно объяснить и фотостимуляцию травления кремния в HF без приложения внешнего смещения, не привлекая уже в качестве обязательного участника электрохимического процесса свободные носители заряда валентной зоны.

При наличии в растворе сильных окислителей, уровень редокс-потенциала которых лежит в валентной зоне кремния, прямая инжекция дырок в результате восстановления молекул окислителя на поверхности кристалла действительно должна вносить определяющий вклад в создание разности потенциалов между полупроводником и электролитом, независимо от характера легирования полупроводника. В модели процессов травления кремния, развиваемой Коласинским [13], именно инжекция дырок в валентную зону считается стадией, лимитирующей скорость растворения кремния. Тогда, если это предположение верно, то скорость растворения либо не должна зависеть от типа и концентрации свободных носителей заряда в полупроводнике, либо всегда должна быть выше для кристаллов $p$-, чем $n$-типа проводимости, причем эта разница должна усугубляться с возрастанием уровня легирования. Последнее вытекает из возможности большего по сравнению с полупроводником $p$-типа сдвига потенциала полупроводника $n$-типа проводимости в положительную сторону вследствие параллельного переноса электронов зоны проводимости на уровни окислителя в растворе. Соответственно край валентной зоны $n$-полупроводника может сместиться ниже относительно редокс-потенциала раствора, чем край валентной зоны полупроводника $p$-типа, что привело бы к снижению вероятности туннельного переноса электронов валентной зоны на вакантные состояния окислителя, а, следовательно, согласно предположению, и скорости травления кристаллов $n$-типа. Аналогичным образом на относительные скорости травления могло бы повлиять и вовлечение в реакцию с анионами $\mathrm{F}^{-}$ собственных носителей заряда кристаллов $p$-типа проводимости.

Мы провели экспериментальное сравнение удельных скоростей растворения кремния различного типа и уровня легирования в концентрированной плавиковой кислоте, содержащей в качестве окислителей трехвалентное железо, пятивалентный ванадий и шестивалентный хром. Для приготовления травящих растворов использовались плавиковая кислота (48\%-я, или $\sim 27 \mathrm{MHF})$, шестиводный хлорид трехвалентного железа $\left(\mathrm{FeCl}_{3} \cdot 6 \mathrm{H}_{2} \mathrm{O}\right)$, пятиокись ванадия $\left(\mathrm{V}_{2} \mathrm{O}_{5}\right)$ и хромовый ангидрид $\left(\mathrm{CrO}_{3}\right)$. Исходная концентрация окислителя выбиралась равной 1 моль/л в пересчете на $\mathrm{Fe}^{+3}$ (наиболее вероятная форма существования в растворе $\left.\left[\mathrm{FeF}_{6}\right]^{-3}\right), \mathrm{V}^{+5}\left(\mathrm{VO}_{2}^{+}\right)$и $\mathrm{Cr}^{+6}\left(\mathrm{CrO}_{3} \mathrm{~F}^{-}\right)$. Железо и ванадий при восстановлении изменяют свою

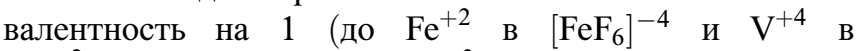
$\mathrm{VO}^{+2}$ ), а хром на 3 (до $\mathrm{Cr}^{+3}$ ); стандартные значения окислительно-восстановительных потенциалов $\left(E_{0}\right)$ равны: $E_{0}\left(\mathrm{Fe}^{+3} / \mathrm{Fe}^{+2}\right)=0.771 \mathrm{~B}, E_{0}\left(\mathrm{VO}_{2}^{+} / \mathrm{VO}^{+2}\right)=0.999 \mathrm{~B}$, $E_{0}\left(\mathrm{CrO}_{4}^{-2} / \mathrm{Cr}^{+3}\right)=1.477 \mathrm{~B}$.

Чтобы минимизировать по времени нестационарную фазу травления кремниевых пластин, их поверхность предварительно загрублялась шлифовкой абразивным порошком с размером зерна 3 мкм. После этого пластины промывались водой, обезжиривались в хлороформе и ацетоне, обрабатывались последовательно 30\%-м раствором аммиака и 10\%-м раствором НF. Одинаковые по площади и предварительно взвешенные образцы кремниевых пластин с различным типом и уровнем легирования вертикально крепились в держателе и травились в одинаковых условиях в течение 1 ч.

Во всех случаях травления кремния в железо- и ванадийсодержащих растворах HF наблюдалось выделение водорода на всем протяжении процесса. Однако в растворе, содержащем в качестве окислителя трехвалентное железо, интенсивность выделения водорода явственно снижалась с уменьшением концентрации свободных носителей заряда в кристаллах, как $n$-, так и $p$-типа проводимости, от $10^{19}$ до $10^{17} \mathrm{~cm}^{-3}$. Травление же кремния в хроматном растворе отличалось первоначально активным, но быстро (в течение $\sim 1$ мин) прекращавшимся выделением водорода. После проведенных обработок образцы промывались водой, высушивались на воздухе и взвешивались.

В железо- и ванадийсодержащих травителях кроме непосредственного растворения кремния результатом обработки становится формирование на поверхности кристаллов двухслойной структуры, состоящей из внешнего слоя мелкодисперсного кремния, светящегося под 


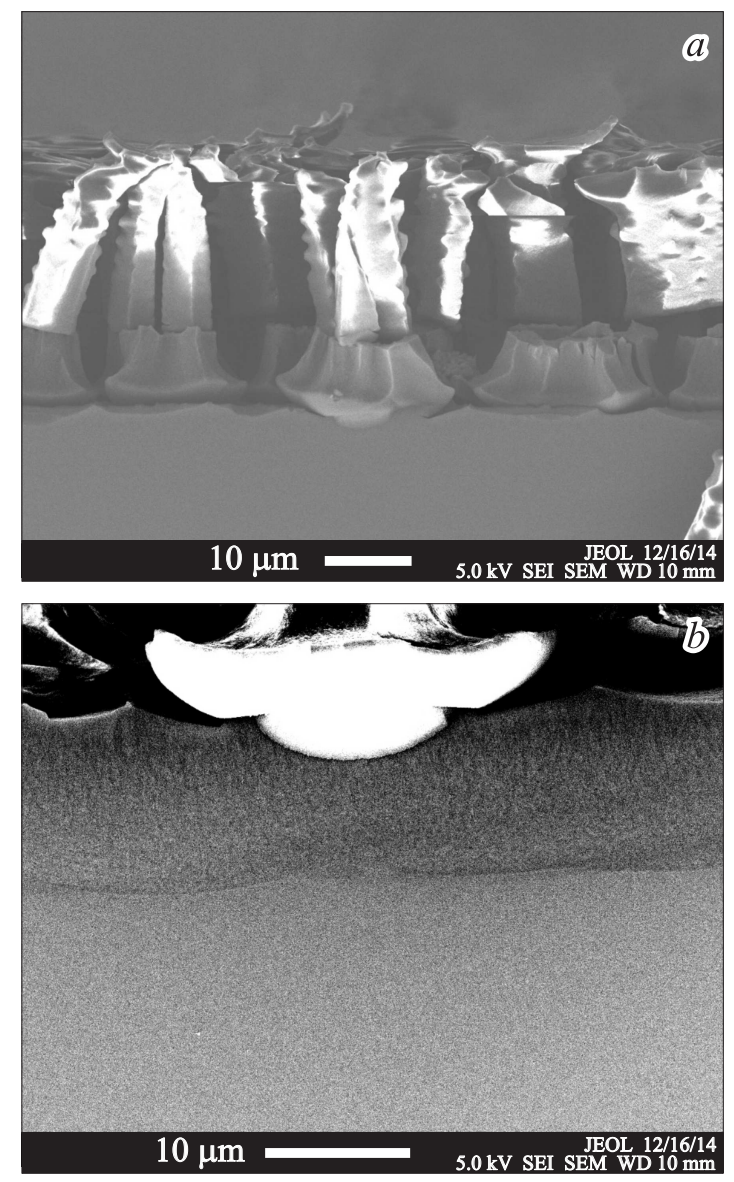

Рис. 3. SEM-изображения двухслойных структур из мелкодисперсной кремниевой фазы и пористого слоя, возникших при травлении $p^{+}-\mathrm{Si}$ в $\mathrm{HF}$, содержащей $\mathrm{V}_{2} \mathrm{O}_{5}(a)$ и $\mathrm{FeCl}_{3}(b)$.

действием ультрафиолетового (УФ) излучения, и нижележащего пористого слоя (рис. 3).

На поверхности пластин $n$-типа проводимости, обработанных в хроматном растворе, не находилось какихлибо слоев модифицированного кремния. Пористые слои с низкой степенью пористости и без покрытия мелкодисперсной люминесцирующей фазой обнаруживались только на пластинах $p$-типа проводимости. На рис. 4 приведены экспериментальные зависимости удельных скоростей растворения кремния $(V)$ от типа и концентрации свободных носителей заряда.

Можно заметить качественное сходство этих зависимостей для железо- и ванадийсодержащих растворов, травление кремния в которых имеет качественно одинаковый характер. При концентрациях свободных носителей заряда обоих знаков на уровне $10^{17} \mathrm{~cm}^{-3}$ и ниже скорости растворения кремния практически не зависят от типа проводимости и степени легирования кристаллов. Однако по величине эти скорости различаются более чем на порядок - более сильному окислителю, 5-валентному ванадию, соответствуют и бо́льшие скорости травления. Для кремния с большими уровнями легирования повышение концентраций свободных носителей заряда приводит к возрастанию скорости растворения в HF, сначала для кристаллов $p$-, затем для $n$-типа проводимости. Обращает на себя внимание особенно резкое увеличение скорости травления кремния $n$-типа проводимости в интервале концентрации электронов от $10^{18}$ до $10^{19} \mathrm{~cm}^{-3}$. При этом для обоих окислителей сильно легированным кристаллам кремния $p$ - и $n$-типа проводимости, представляющим собой полупроводники, находящиеся на пороге вырождения, соответствуют максимальные и близкие друг к другу значения скоростей травления. Показательно также, что максимальные значения скоростей травления в $\mathrm{Fe}^{+3}$-содержащем растворе $\mathrm{HF}$ достигают величин, соответствующих скоростям травления кремния в ванадиевом растворе. Наблюдаемые изменения кинетики растворения кремния свидетельствуют о том, что инжекция дырок в валентную зону, сопровождающая восстановление окислителя, в общем случае не может являться стадией, лимитирующей скорость травления в режиме порообразования. Следовательно, поскольку лимитирующая стадия не связана с доставкой носителей заряда, ее можно искать лишь среди гетерогенных электрохимических процессов, ответственных за разрушение решетки кристалла.

Подтверждением такого вывода может служить и неожиданно низкая, на первый взгляд, скорость растворения кремния в $\mathrm{HF}$ в присутствии наиболее сильного окислителя - шестивалентного хрома $\left(E_{0}\left(\mathrm{CrO}_{4}^{-2} / \mathrm{Cr}^{+3}\right)=1.477 \mathrm{~B}\right)$, инжектирующего в элементарном акте восстановления в валентную зону три дырки. Значения этой скорости практически не обнаруживают зависимости от типа и уровня легирования кремния и оказываются в 3-4 раза ниже величин, регистрируемых для растворов с более слабыми окисли-

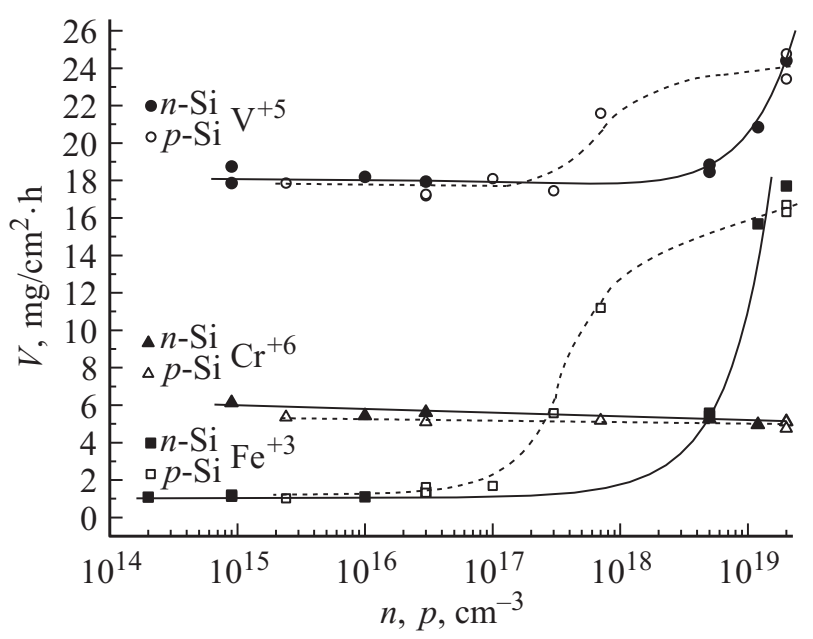

Рис. 4. Экспериментальные зависимости удельных скоростей растворения кремния $(V)$ от типа проводимости и концентрации свободных электронов $(n)$, дырок $(p)$ при травлении в плавиковой кислоте (48\%-й $\mathrm{HF})$, содержащей $1 \mathrm{M} \mathrm{Fe}^{+3}\left(\mathrm{FeCl}_{3}\right)$, $1 \mathrm{M} \mathrm{V}^{+5}\left(\mathrm{~V}_{2} \mathrm{O}_{5}\right)$ или $1 \mathrm{M} \mathrm{Cr}^{+6}\left(\mathrm{CrO}_{3}\right)$. 
телями, меняющими свою валентность на 1. Очевидно, что отмеченные различия связаны с качественным изменением характера травления кремния в хроматном растворе. Начинаясь как порообразование, на что указывает первоначальное выделение водорода, процесс переходит в фазу сплошного травления с образованием продуктов полного окисления кремния, так же как это происходит при переходе к полирующему травлению с повышением потенциала кремниевого анода в обычном процессе электрохимического травления. Сделанные наблюдения доказывают, что скорости растворения полупроводниковых кристаллов кремния в окисляющих растворах НF лимитируются не кинетикой переноса электронов через межфазную границу, а определяются достигающейся в заданных условиях скоростью гетерогенных химических процессов, обеспечивающих отделение атомов от решетки кристалла. Иными словами, не скорость окисления лимитирует скорость растворения полупроводника, а, напротив, скорость разрушения химических связей в кристалле, реализующаяся в конкретном электрохимическом процессе, ограничивает скорость восстановления окислителя.

Обнаруженные вариации скоростей растворения кремния в плавиковой кислоте с различными окислителями могут быть объяснены следующим образом.

Преодоление активационного барьера для начала электрохимической реакции с участием материала электрода требует достижения определенной пороговой величины падения потенциала в слое Гельмгольца на границе раздела полупроводник-электролит $\left(\varphi^{\mathrm{H}}\right)$. В зависимости от типа и уровня легирования заряжение окисляющегося полупроводника относительно раствора сопровождается неодинаковым распределением общего падения потенциала между слоем объемного заряда внутри кристалла и слоем адсорбированных на нем частиц электролита. Для вырожденных металлизированных материалов обоих типов проводимости границы энергетических зон сдвигаются вместе с уровнем Ферми относительно энергетических уровней в растворе, и поэтому практически все падение потенциала оказывается локализованным в слое Гельмгольца. Это объясняет высокую и практически одинаковую при порообразовании скорость травления кремния $p$ - и $n$-типа проводимости с концентрациями носителей заряда на уровне $10^{19} \mathrm{~cm}^{-3}$. В кремнии с меньшими уровнями легирования формируются слои объемного заряда, на которых происходит падение части наведенного потенциала. Для невырожденных полупроводниковых кристаллов повышение межфазной разности потенциалов вначале ведет к положительному сдвигу величины падения потенциала в области пространственного заряда, слабо отражаясь на состоянии слоя Гельмгольца. Однако с приближением к поверхностному вырождению большая часть дополнительного падения потенциала сосредоточивается на межфазной границе $[15,16]$ и в какой-то момент достигается пороговая величина для начала реакций, ведущих к порообразованию. Поскольку в материалах $n$-типа проводимости необходимое для достижения поверхностного вырождения изменение величины падения потенциала в области пространственного заряда, как правило, больше, чем в материалах $p$-типа, для достижения порогового значения скачка потенциала в слое Гельмгольца требуется бо́льшая глубина окисления кремния (величина сдвига уровня Ферми полупроводника от начального положения в сторону уровня редокс-потенциала травящего раствора), чем в случае кристаллов $p$-типа проводимости. С этим, по-видимому, можно связать начало подъема скорости травления кристаллов $p$-типа проводимости при меньших значениях концентраций свободных носителей заряда, чем для кремния $n$-типа, что особенно заметно при использовании наиболее слабого окислителя - трехвалентного железа.

В результате действия достаточно сильных окислителей наведенные значения скачков потенциала в слое Гельмгольца уже независимо от уровня легирования кремниевых кристаллов могут становиться существенно выше пороговых значений для гетерогенных реакций, протекающих в режиме порообразования или даже в режиме сплошного травления. В этом случае можно ожидать, что скорости травления $(V)$ окажутся сопоставимыми с их максимальными значениями, определяемыми величинами констант скоростей для процессов реализующегося типа: $V=k_{0} \exp \left[\left(E^{*}-e \varphi\right) / k T\right]$, где $k_{0}$ - константа скорости реакции, $E^{*}$ - высота активационного барьера, $\varphi$ - падение потенциала на межфазной границе. В такой интерпретации нетрудно объяснить сравнительно слабую (для ванадиевого раствора) или отсутствующую (для хроматного раствора) зависимость скорости растворения кремния в НF от электрофизических параметров кристалла.

\section{3. Условия инициирования и химические механизмы порообразования и однородного травления кремния}

Обратимся теперь собственно к механизму гетерогенных электрохимических процессов, приводящих к порообразованию в кремнии. Ранее нами рассматривалось порообразование, возникающее как начальная фаза анодного травления в кристаллах $\mathrm{A}^{\mathrm{III}} \mathrm{B}^{\mathrm{V}}$ исключительно $n$-типа проводимости и, в отличие от кремния, способное развиваться в электролитах со многими галогенидными и оксо-анионами [14]. Проведенный анализ зависимостей величин порогового напряжения начала порообразования от уровня легирования кристаллов, типа участвующих в реакции анионов и их концентрации, $p \mathrm{H}$ растворов, кристаллографической ориентации поверхности травящихся кристаллов совместно с анализом результатов исследования химического состава продуктов реакций порообразования и изучения анизотропии распространения пор в кристаллах позволил обосновать 
принципиально отличную от существующих модель процессов дискретного анодного травления полупроводниковых кристаллов. Эта модель основана на представлении о кооперативных реакциях нуклеофильного замещения, развивающихся под действием скачка потенциала в слое Гельмгольца между хемосорбированными анионами, образующими плотное адсорбционнное покрытие, и координационно-насыщенными атомами нижележащего слоя решетки. Химический механизм таких гетерогенных реакций аналогичен хорошо известным в органической химии гомогенным реакциям нуклеофильного замещения с атакой нуклеофила на антисвязывающую орбиталь исходной молекулы и разрушением химической связи с уходящей группой вдоль направления нуклеофильной атаки (реакции $\mathrm{S}_{\mathrm{N}} 2$ ). Специфика рассматриваемых нами реакций заключается в том, что они протекают на поверхности кристалла, представляющего собой периодическую пространственную структуру, образованную непрерывно связанными друг с другом атомами (трехмерный полимер). Поэтому единичный акт реакции нуклеофильного замещения, происходящий с отдельным атомом, включенным в решетку кристалла, привел бы к значительным деформациям его связей с окружением и резкому локальному повышению уровня свободной энергии системы, что термодинамически неоправданно. В этом отношении более предпочтительным оказывается кооперативный путь процесса, в элементарный акт которого вовлекается достаточно большая группа компактно расположенных адатомов и атомов решетки кристалла.

Протекание такой реакции обеспечивается туннелированием электронов с заполненных уровней несвязывающих валентных орбиталей адатомов (доноров), образующих плотное адсорбционное покрытие, на сблизившиеся с ними по энергетическому положению вакантные уровни антисвязывающих или несвязывающих орбиталей координационно-насыщенных атомов приповерхностного слоя кристалла (акцепторов). Последние уровни лежат в зоне проводимости полупроводника, а их сближение с уровнями валентных электронов адатомов происходит в ходе повышения анодного смещения за счет увеличения падения потенциала в слое, образованном хемосорбированными анионами (внутренняя часть слоя Гельмгольца), включая падение потенциала во внешнем атомном слое кристалла $\left(\Delta \varphi^{\mathrm{H}}+\varphi_{\text {surf }}\right)$ (см. рис. 5). При достижении некоторой пороговой величины $\left(\varphi_{c}\right)$ становится возможным развитие самосогласованного, кооперативного процесса переноса химической связи каждого вовлеченного адатома с атома внешнего атомного слоя кристалла на ближайший координационно-насыщенный атом нижележащего слоя. Такой процесс реализуется во множестве локальных, компактных областей межфазной границы как совокупность корреляционно-связанных крупномасштабных флуктуаций. При этом в каждом пятне реакции возникает система сопряженных переходных комплексов, синхронная релаксация которых сопровождается разрывом химических связей с очередным слоем атомов в кристалле. Образовывавшие эти связи электроны возбуждаются на уровни соответствующих

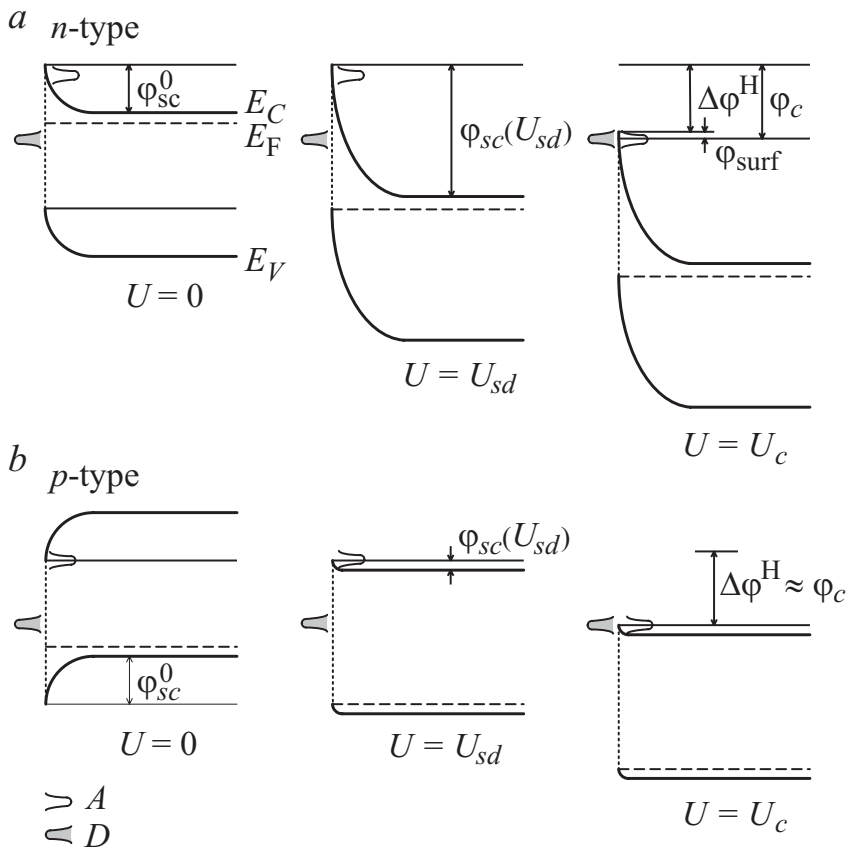

Рис. 5. Изменение взаимного положения краев энергетических зон полупроводника и энергетических уровней атомных орбиталей, участвующих в образовании переходных комплексов кооперативной реакции нуклеофильного замещения на поверхности кристалла для полупроводника $n$ - $(a)$ и $p$-типа $(b)$ проводимости. $A-$ энергетические уровни вакантных антисвязывающих или несвязывающих орбиталей атомов приповерхностного слоя кристалла; $D-$ уровни энергии неподеленных пар электронов на хемосорбированных анионах; $\varphi_{s c}-$ падение потенциала в слое объемного заряда полупроводника; $U_{s d}$ - напряжение анодного смещения, соответствующее началу поверхностного вырождения; $\Delta \varphi^{\mathrm{H}}-$ изменение падения потенциала в слое Гельмгольца; $\varphi_{\text {surf }}-$ падение потенциала во внешнем атомном слое решетки кристалла; $\varphi_{c}-$ критическая величина падения потенциала для начала кооперативной реакции нуклеофильного замещения на поверхности кристалла, $U_{c}-$ соответствующее ей напряжение анодного смещения.

антисвязывающих или несвязывающих состояний, т. е. в зону проводимости полупроводника. Таким образом осуществляется акт травления, в котором от кристалла отделяются полимерные группировки, включающие атомы двух смежных слоев его решетки, а высвободившиеся электроны экстрагируются из зоны реакции в градиенте потенциала, создающемся внешним источником. Именно эти электроны и обеспечивают протекание анодного тока. Цикл завершается заселением оборванных связей (электрофильных центров адсорбции), остающихся на отделяемом фрагменте, и на вновь образованной поверхности кристалла анионами, поступающими из электролита. В описанном процессе самоорганизующегося локального травления реализуется неполное окисление материала полупроводника, поскольку отделяющиеся от кристалла полимерные группировки сохраняют часть существовавших в кристалле химических связей. Именно поэтому обсуждаемый здесь кооперативный химический 
процесс в термодинамическом отношении более выгоден, чем эквивалентный ему по результату последовательный отрыв от решетки единичных атомов. В то же время очевидно, что вероятность элементарного акта кооперативной реакции (частота повторения) должна быть много меньше вероятности элементарного акта перевода из кристалла в раствор единичного атома, в том случае, конечно, если достигнуты условия для преодоления соответствующего активационного барьера. В этом контексте становится понятным, почему порообразование всегда развивается как начальный этап анодного процесса и переходит в сплошное травление при возрастании величины анодного смещения. Другим важным следствием кооперативного механизма элементарного акта реакции порообразования становится импульсный, скачкообразный характер продвижения ее фронта на дне каждой отдельной поры.

Конкретный химический механизм кооперативной реакции нуклеофильного замещения определяется характером вакантных орбиталей атомов приповерхностного слоя кристалла, обладающих наиболее низкими уровнями энергии, ближайшими к положению потолка валентной зоны. Очевидно, что заполненные состояния, соответствующие неподеленным парам электронов на адсорбированных анионах, в отсутствие создаваемого извне поля могут располагаться только в области валентной или запрещенной зоны полупроводника. В прямозонных полупроводниках с тетраэдрической структурой (таких как GaAs и $\mathrm{InP}$ ) определяющим ширину запрещенной зоны электронным переходам в точке Г зоны Брюллюэна можно сопоставить переходы со связывающих на антисвязывающие молекулярные $s p^{3}$-орбитали. Это диктует протекание нуклеофильной атаки вдоль направлений связей в кристалле, т.е. кристаллографических направлений $\langle 111\rangle$, и формирование первичного продукта реакции анионов $\mathrm{X}$ с соединением $\mathrm{AB}$, отвечающего стехиометрии $\left(\mathrm{ABX}_{2}\right)_{n}$. Полярность же направлений распространения пор $(\langle 111\rangle \mathrm{B}$ или $\langle 111\rangle \mathrm{A})$ определяется участием в реакции анионов, химически адсорбированных соответственно на атомах В или А подрешетки кристалла со структурой сфалерита [15].

В кристаллах кремния ширине запрещенной зоны соответствуют непрямые электронные переходы с энергией 1.12 эВ на шестикратно вырожденные состояния $\Delta$-долины зоны проводимости, что значительно ниже энергии прямых переходов $\sim 3.4$ эВ в центре зоны Брюллюэна (рис. 6). Различия в симметрии долин зоны проводимости, в которых находятся уровни, соответствующие орбиталям, участвующим в образовании химических связей переходных комплексов, предполагают различный тип гибридизации электронов на этих связях. Поэтому, в отличие от реакций нуклеофильного замещения на поверхности прямозонных полупроводников $\mathrm{A}^{\mathrm{III}} \mathrm{B}^{\mathrm{V}}$, разумно предположить, что кремний в подобных реакциях реализует свои несвязывающие $d^{2} s p^{3}$-орбитали, как это происходит при образовании комплексных ионов $\left[\mathrm{SiF}_{6}\right]^{-2}$. Из химии кремнийорганических соединений известно также, что многие реакции

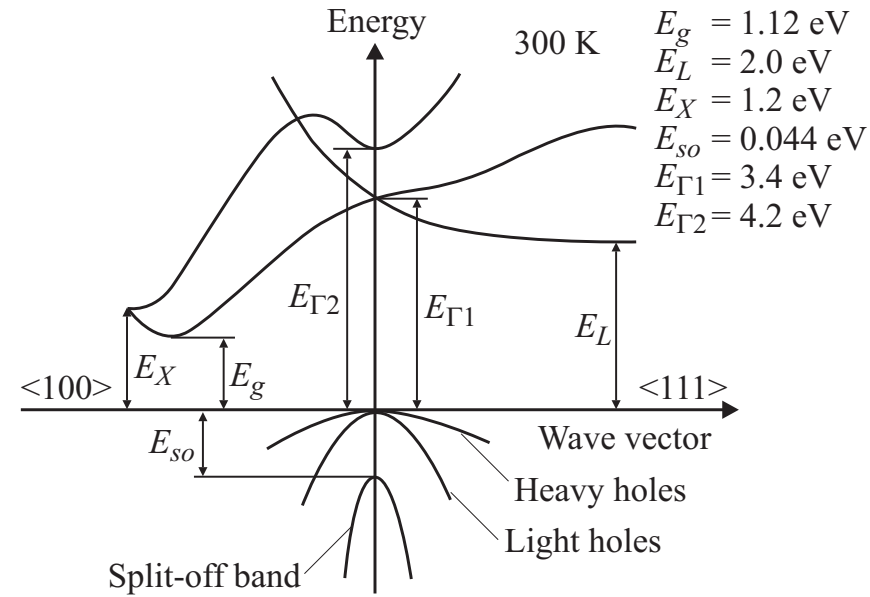

Рис. 6. Структура энергетических зон электронов в кристаллическом кремнии (из http://www.ioffe.ru/SVA/NSM/ Semicond/Si/bandstr.html), $E_{\Delta}=E_{g}$.

$S_{\mathrm{N}} 2$ нуклеофильного замещения при атоме кремния происходят без инверсии конфигурации молекулы и, следовательно, в формировании переходных комплексов задействуются не антисвязывающие $s p^{3}$-орбитали, а вакантные несвязывающие орбитали, образование которых возможно только при участии $d$-состояний атома кремния [17]. Заметим также, что корректный расчет параметров зоны проводимости кремния в методе сильной связи с правильным определением положений экстремумов в $k$-пространстве, значений эффективных масс и ширины запрещенной зоны оказался возможным только при учете в базисных функциях $d$-орбиталей атома кремния [18].

Из предлагаемой нами модели кооперативного механизма элементарного акта реакции нуклеофильного замещения на поверхности кремниевого кристалла следует, что после релаксации системы сопряженных переходных комплексов с диссоциацией двух связей $\mathrm{Si}-\mathrm{Si}$ у каждого из вовлеченных в процесс атомов решетки должен образовываться первичный полимерный продукт со стехиометрией $\left(\mathrm{SiF}_{2}\right)_{n}$. Иными словами, прорастание пор в кремнии должно сопровождаться отделением от решетки линейных цепочек из атомов кремния, каждый из которых связан с 2 атомами фтора. В кристаллах кремния структурные элементы, состоящие из цепочек связанных атомов, принадлежат сдвоенным плоскостям (100). Соответственно в направлениях семейства $\langle 100\rangle$ единичный элементарный акт кооперативной реакции должен продвигать фронт процесса травления сразу на полпериода решетки в глубь кристалла. Очевидно, что реакции нуклеофильного замещения с участием адатомов фтора могут протекать не только на поверхностях кремния с кристаллографическими ориентациями (001), однако в этом случае для образования отделяющегося от кристалла полимерного продукта требуются повторные акты кооперативного процесса. Поэтому направления $\langle 100\rangle$ должны становиться на- 
$a$

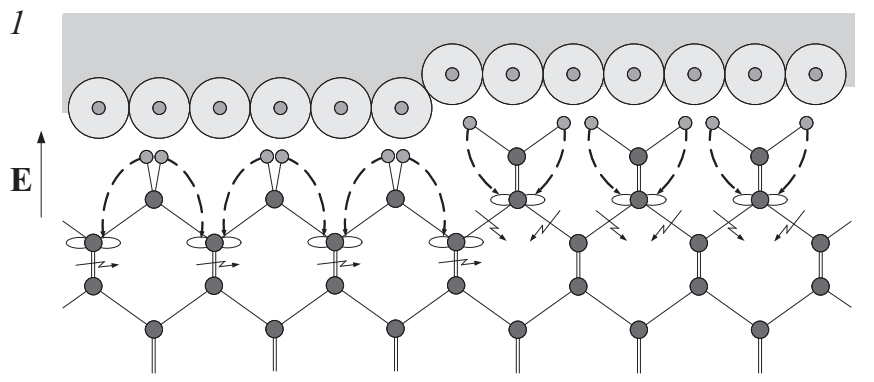

$b$

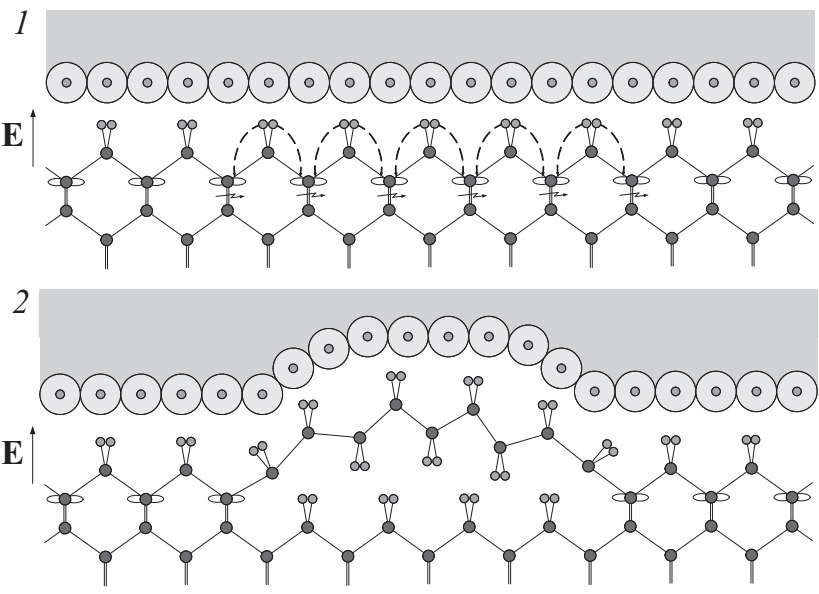

Рис. 7. Схема процессов кооперативной нуклеофильной атаки хемосорбированных анионов фтора на координационно-насыщенные атомы кремния подповерхностного слоя решетки и отделения полимерных продуктов реакции. $а$ : нуклеофильная атака на поверхности (100) Si в области смежных террас, разделенных моноатомной ступенью - вид в сечении плоскостью (011) (1) и вид в направлении, перпендикулярном поверхности (2). $b$ : последовательные стадии $(1-4)$ образования и отделения полимерной цепочки $\left(\mathrm{SiF}_{2}\right)_{n}$ от кристалла. $\mathrm{F}_{\text {sol }}^{-}$- анионы фтора, сольватированные в растворе молекулами $\mathrm{HF}$ и $\mathrm{H}_{2} \mathrm{O} ; \mathrm{F}^{-\delta}(\mathrm{Si})-$ анионы фтора, хемосорбированные поверхностью кремния (адатомы фтора); $\mathrm{Si}$ — атомы кремния в решетке кристалла; $\mathrm{Si}\left(d^{2} s p^{3}\right)$ атомы кремния подповерхностного слоя решетки с локализованными на них вакантными $d^{2} s p^{3}$-орбиталями; Н - атомы хемосорбированного водорода. $\mathbf{E}$ - вектор электрического поля, действующего на межфазной границе; штриховые стрелки указывают направления нуклеофильной атаки, стрелки с зигзагом показывают разрыв химических связей Si-Si.

правлениями наиболее быстрого распространения пор и доминировать в структуре пористых слоев, что соответствует экспериментальным наблюдениям.

Поскольку реальные поверхности (100) Si представляют собой комбинацию фрагментов атомно-гладких террас, разделенных моноатомными ступенями (о чем свидетельствует отсутствие оптической анизотропии у поверхностей (100) Si), отделяющиеся в ходе их травления цепочки атомов ориентируются во взаимно перпендикулярных направлениях $\langle 110\rangle$ и $\langle 1 \overline{1} 0\rangle$ (рис. 7,a). Это, в свою очередь, предполагает тенденцию к формированию пор, сечение которых приближается к квадрату с ориентацией сторон вдоль указанных направлений, что также соответствует действительности (см., например, рис. $1, c)$. Рис. $7, b$ иллюстрирует протекание нуклеофильной атаки адсорбированного фтора на атомы кремния второго слоя на участке атомно-гладкой поверхности (100) и последующие процессы, завершающие единичный цикл травления решетки. Каждый такой цикл продвижения фронта реакции предполагает этап релаксации с выделением тепла в пятне реакции, что поддерживает локальный уровень активации при продвижении поры в глубь кристалла. Нельзя исключать и того, что после прохождения вслед за реакцией нуклеофильного замещения процессов электродиффузии анионов фтора из раствора и заполнения ими вновь образованной поверхности кристалла (рис. 7, $b, 3)$ возникающие механические напряжения не всегда оказываются достаточными для разрыва концевых связей сформировавшихся цепочек $\left(\mathrm{SiF}_{2}\right)_{n}$. В этом случае последую- 
щий элементарный акт кооперативного процесса должен протекать под слоем неотделившихся еще продуктов, что ведет к непостоянству размеров пятна реакции на дне поры и появлению дополнительной низкочастотной модуляции скорости травления, связанной с отделением накапливающихся полимерных продуктов. Этим же может объясняться выраженная шероховатость стенок пор в кремнии и склонность их к ветвлениям.

Последующее взаимодействие отделившихся от кристалла группировок с раствором электролита завершается образованием конечных продуктов полного окисления кремния и выделением водорода:

$$
\left(\mathrm{SiF}_{2}\right)_{n}+4 n \mathrm{HF}=n \mathrm{H}_{2} \mathrm{SiF}_{6}+n \mathrm{H}_{2} \text {. }
$$

Не исключен также параллельно протекающий процесс диспропорционирования полимерного продукта, фрагменты которого могут оставаться прикрепленными к стенкам пор, что должно приводить к образованию кластеров кремния, удерживающихся в объеме пор на внутренней поверхности скелетного кристалла:

$$
\left(\mathrm{SiF}_{2}\right)_{n}=(n / 2) \mathrm{SiF}_{4}+(n / 2) \mathrm{Si}
$$

C наличием такой мелкодисперсной фазы можно связать наблюдающуюся фотолюминесценцию пористых слоев кремния в видимой области, а также присутствие в их составе разупорядоченной аморфизованной компоненты [19]. Частичное диспропорционирование первичного полимерного продукта можно считать и основной причиной отклонения оцениваемой величины эффективной валентности кремния при порообразовании в бо́льшую сторону от 2.

Заполняя объем каждой прорастающей в кристалл поры, первичные полимерные продукты кооперативной реакции могут выполнять также функцию среды, селективно сорбирующей из электролита анионы фтора и обеспечивающей их электродиффузию к фронту реакции на дне поры, т.е. служить аналогом твердого электролита. Действительно, как и в молекулах $\mathrm{SiF}_{4}$, атомы кремния в цепочках $\left(\mathrm{SiF}_{2}\right)_{n}$ должны быть способны образовывать координационные связи с анионами фтора за счет тех же вакантных $d^{2} s p^{3}$-гибридных орбиталей, создавая анионные комплексы $\left(\mathrm{SiF}_{2}\right)_{n} \mathrm{~F}_{x}^{-}$. Под действием электрического поля анионы $\mathrm{F}^{-}$получают возможность направленно мигрировать в пространстве пор, совершая переходы между атомами кремния соседних группировок. Предположение о заполнении объема пор промежуточными продуктами реакции, селективно транспортирующими анионы фтора, может объяснить неожиданно слабое влияние диффузионного массопереноса на скорость прорастания капиллярных каналов пор, распространяющихся на сотни мкм в глубь кристалла. В противном случае выделяющийся в ходе реакции на дне пор водород должен был бы значительно затруднять проникновение в них электролита и тормозить массоперенос HF к фронту реакции. Существование в порах промежуточных продуктов неполного окисления кремния объясняет и необычно продолжительное выделение водорода из пористых слоев после прекращения анодирования.

В условиях анодного травления с зарождением пор и началом протекания через них ионного тока потенциал поверхности кристалла падает и области, не задействованные в реакции, оказываются шунтированными токовыми каналами пор. Такие выпадающие из электрохимического процесса поверхности кремния, включая поверхности стенок пор, постепенно гидрируются, взаимодействуя с проникающими в поры молекулами HF по упоминавшемуся выше механизму замещения водородом внешнего слоя фторированных атомов решетки (см. рис. $7, b, 4)$. Этим обеспечивается химическая пассивация сохраняющихся фрагментов кристалла, образующих собой пористый кремний. Продвигающиеся в объем анодно-поляризованного кристалла активные фронтальные области пор получают возможность ветвиться, сближаясь до тех пор, пока разделяющие их перегородки не перестанут быть токопроводящими, достигая удвоенной толщины слоя объемного заряда в полупроводнике [20,21], а также приобретая бо́льшую, чем в исходном кремнии, ширину запрещенной зоны вследствие эффектов размерного квантования [22]. После этого формируется стационарный фронт продвижения массива пор, который может распространяться в глубь кристалла на сотни мкм.

В силу кооперативного характера процессов, обеспечивающих распространение пор в кристалле, их скорость не может возрастать неограниченно, демпфируя рост скачка потенциала на межфазной границе с повышением величины анодного смещения $(\Delta U)$. Поэтому начиная с некоторых его значений величина $\Delta \varphi^{\mathrm{H}}$ переходит к быстрому возрастанию при дальнейшем повышении $\Delta U$. Вместе с $\Delta \varphi^{\mathrm{H}}$ увеличиваются энтальпийные составляющие изменения свободной энергии для всех возможных гетерофазных реакций с участием анионных компонентов раствора, формирующих адсорбционный слой [15], и снижаются их активационные барьеры. Тогда при достижении определенной величины приложенного напряжения начинает преодолеваться активационный барьер для некооперативного процесса непосредственной атаки сольватированных в растворе анионов фтора на связи атомов во внешнем слое кристалла и становится возможным отделение от решетки индивидуальных атомов кремния с образованием продукта его полного окисления:

$$
\mathrm{Si}+4 \mathrm{~F}_{\mathrm{sol}}^{-}=\mathrm{SiF}_{4}+4 e^{-}+\mathrm{sol},
$$

где sol - молекулы сольватной оболочки анионов фтора, $e$ - электроны, переходящие в зону проводимости анодно-поляризованного кристалла.

Благодаря гораздо более высоким по сравнению с кооперативными процессами скоростям (частотам) элементарных актов таких реакций происходит переход от порообразования к сплошному травлению кремния, несмотря на то что кооперативная реакция остается 
термодинамически более выгодным процессом. На поляризационных кривых этому переходу всегда соответствует снижение тока ячейки [3], что при одновременном возрастании эффективной валентности кремния в электрохимической реакции означает резкое падение скорости его растворения.

Во фторидных растворах с низкой активной концентрацией анионов фтора, таких как безводные растворы НF, для создания необходимой концентрации физсорбированных анионов в плотной части двойного электрического слоя требуются гораздо более высокие напряжения, и условия для развития реакции (3) могут не достигаться. Поэтому в безводных растворах $\left(\mathrm{HF}-\mathrm{CH}_{3} \mathrm{CN}\right)$ область изменения анодного потенциала кремния, в которой реализуется порообразование, оказывается значительно шире, чем в водных растворах [23].

Обратная ситуация возникает при травлении кремния в концентрированном водном растворе $\mathrm{H}_{2}\left[\mathrm{SiF}_{6}\right]$ (раствор приготавливался добавлением в плавиковую кислоту сверхстехиометрического количества аморфной двуокиси кремния $\mathrm{SiO}_{2}$ ), в котором анодный процесс происходит исключительно по механизму сплошного (полирующего) травления без выделения водорода. В этом случае для начала любых гетерогенных процессов требуется диссоциация комплексного иона $\left[\mathrm{SiF}_{6}\right]^{-2}$, достигаемая лишь при падениях потенциала на межфазной границе, превышающих величину, достаточную для протекания реакции (3).

Процессы травления кремния в HF с участием окислителей и процессы анодного травления тождественны, однако условия их протекания различаются принципиально. В растворах с окислителем гетерогенные катодные (восстановление окислителя) и анодные (растворение кремния) процессы пространственно совмещены и, следовательно, должны флуктуационным образом сменять друг друга на микроскопических участках поверхности. Кроме того, при травлении с окислителями не происходит снижения потенциала внешней поверхности кристалла и анодные реакции не локализуются исключительно на фронте прорастания пор. В этом случае в областях кристалла между первоначально сформировавшимися порами образуются все новые пятна травления и стенки пор продолжают разрушаться, пока размеры остающихся фрагментов решетки не окажутся малы настолько, что вследствие эффектов размерного квантования уровни, отвечающие валентной зоне, не опустятся ниже уровня редокс-потенциала раствора. Как следствие, скорости окисления и последующего растворения таких частиц кремния резко уменьшаются, что и обеспечивает их длительное существование в травящем растворе [24]. Это же справедливо и для кластеров кремния, появляющихся при диспропорционировании первичных полимерных продуктов кооперативной реакции, вызывающей порообразование. Рассматриваемые особенности поведения наноразмерных полупроводниковых частиц объясняют образование на кремнии в растворах HF с умеренно сильными окислителями тонких пористых слоев, покрытых мелкодисперсным кремнием, люминесцирующим в видимой области спектра на длине волны, зависящей от величины окислительно-восстановительного потенциала раствора и продолжительности травления.

Завершая обсуждение электрохимического порообразования в кремнии, следует остановиться на объяснении уникальности фторидных электролитов в осуществлении этого процесса. В свете предложенной модели исключительная активность фтора может быть объяснена его предельно высокой электроотрицательностью (3.98 по Поллингу) и соответственно высоким эффективным зарядом хемосорбированных поверхностью кремния анионов (адатомов). Теоретические оценки дают для эффективного заряда $\mathrm{F}$ в группировках $=\mathrm{SiF}_{2}$ на кремнии величину $0.66 e$ [25]. Исходный уровень энергии валентных электронов свободного аниона $\mathrm{F}^{-}$(сродство к электрону атома фтора) составляет -3.45 эВ. Поэтому неудивительно, что уровни несвязывающих орбиталей адатомов фтора, потерявших сольватную оболочку, могут оказаться лежащими в запрещенной зоне кремния немного ниже края зоны проводимости (-4.05 эВ) (см. рис. 2), тем более что на границе раздела аноднополяризованного кристалла с электролитом хемосорбированные анионы находятся в контакте с отрицательно заряженными физсорбироваными анионами.

Предположение о достаточной близости энергетического положения неподеленных пар электронов на адатомах фтора к зоне проводимости согласуется с наблюдавшимся спонтанным образованием пор в сильно легированном $n^{+}-\mathrm{Si}$, экспонировавшемся в подогретой до $75^{\circ} \mathrm{C}$ плавиковой кислоте. Действительно, максимально возможное увеличение скачка потенциала в слое Гельмгольца за счет сдвига краев зон вырожденного кремния $n$-типа при установлении электрохимического равновесия с водородной редокс-системой раствора НF $(p \mathrm{H} \sim 1)$ может составить не более $\sim 0.4$ эВ. Этого, тем не менее, оказывается достаточно для начала на кремниевой поверхности окислительно-восстановительных процессов с выделением областей устойчивого развития анодной реакции порообразования.

\section{4. Условия зарождения и размер пор в кремнии}

Спонтанное выделение на структурно-однородной границе раздела положительно заряженного полупроводника с электролитом локальных областей активации кооперативной атаки адатомов-нуклеофилов на атомы приповерхностного слоя решетки кристалла находит близкую аналогию в явлениях зародышеобразования новой фазы.

Обсуждаемая здесь модель порообразования предполагает, что минимальной величине движущей силы гетерогенного химического процесса - скачка потенциала между слоем хемосорбированных атомов фтора и приповерхностным слоем атомов кремния $\left(\varphi_{c}\right)$, способной обеспечить прохождение кооперативной реакции, соответствует условие отсутствия возмущений со стороны 
не вовлеченной в этот процесс области кристалла. Это равносильно требованию синхронного участия в реакции всех адатомов по всей поверхности межфазной границы. Очевидно, однако, что для макроскопического кристалла вероятность столь крупномасштабной флуктуации бесконечно мала. Такое состояние системы сопоставимо с состоянием изолированной объемной фазы при термодинамических параметрах, отвечающих условию двухфазного равновесия, а превышение достигаемой величиной $e \Delta \varphi$ порогового значения $е \varphi_{c}$ (обозначим его $e \delta \varphi)-$ с энергетическим выражением пересыщения для этой фазы.

Аналогом свободной поверхностной энергии зародыша новой фазы в данном случае служит величина энергетического вклада сегрегации полимерного продукта реакции (цепочек атомов $\left.\left(\mathrm{SiF}_{2}\right)_{n}\right)$, снижающая тепловой эффект кооперативного процесса. При этом можно представить три варианта завершения элементарного этапа продвижения фронта реакции в кристалл на полпериода решетки: с поворотом отслоившейся цепочки на $180^{\circ}$ вокруг концевых атомов (см. рис. $7, b, 2$ ); с отрывом одного конца цепочки от кристалла; с полным отделением цепочки и переходом ее в раствор (рис. 7, $b, 3$ ). Понятно, что прорастание поры в глубь кристалла предполагает удаление из нее продуктов реакции и третий вариант протекания процесса должен определять пороговые условия для устойчивого развития пор. В первом приближении энергия, затрачиваемая на отделение продукта реакции от кристалла, может быть выражена как $E_{D}=\left[2 E_{\mathrm{Si}-\mathrm{Si}}+E_{\mathrm{ch}}(n)\right]$, где $E_{\mathrm{Si}-\mathrm{Si}}-$ энергия разрыва химической связи $\mathrm{Si}-\mathrm{Si}\left(1.82\right.$ эВ) и $E_{\mathrm{ch}}(n)-$ суммарная энергия деформации химических связей в отделяемом полимерном продукте к моменту отрыва его от решетки, обусловленная главным образом угловыми деформациями связей $\mathrm{Si}-\mathrm{Si}$ в цепочке отсоединяющихся атомов. Можно лишь сказать, что последняя величина равна нулю при $n=1$ и монотонно возрастает с увеличением $n$. Завершение элементарного этапа кооперативной реакции травления кристалла отщеплением цепочки из $n$ атомов кремния требует превышения критического значения падения напряжения в области межфазной границы на величину $\delta \varphi$, компенсирующую вклад $E_{D}$ в тепловой эффект реакции, в пересчете на один атом кремния, т. е. $\left[2 E_{\mathrm{Si}}-\mathrm{Si}+E_{\mathrm{ch}}(n)\right] / n<e \delta \varphi$. Хотя, не прибегая к оценкам с использованием методов численного моделирования, трудно определить характер зависимости $E_{\mathrm{ch}}(n)$, маловероятно, что она сверхлинейна по отношению к изменению $n$. Поэтому, величина $E_{D} / n$ вслед за резким падением с началом роста числа атомов кремния в отделяемых продуктах должна перейти к весьма медленному снижению начиная уже с $n \approx 10-20$, т. е. при длине цепи $\sim(4-8)$ нм. Это означает, что увеличение $e \delta \varphi$ вместе с повышением анодного смещения от порогового значения (плотности анодного тока от нуля) должно приводить к быстрому уменьшению минимально возможного размера способных к отделению фрагментов решетки кремния и соответственно порогового размера

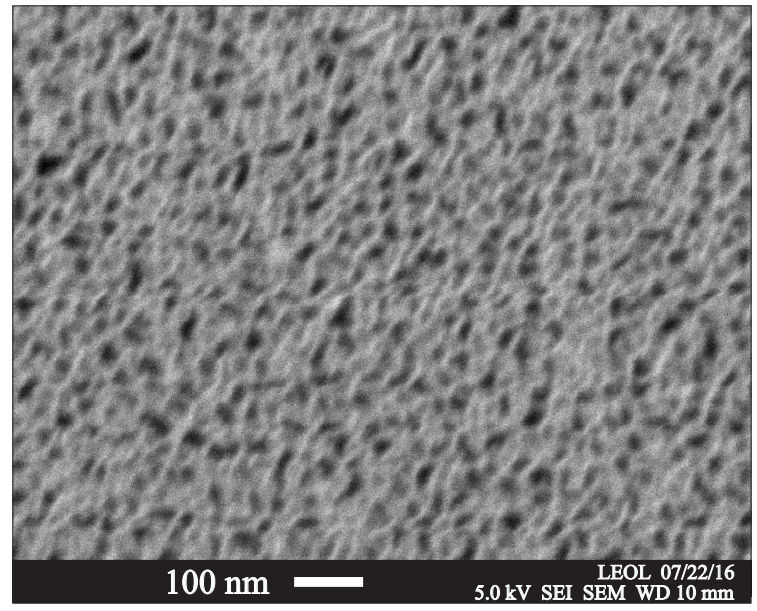

Рис. 8. Поверхность пористого слоя, полученного на пластине $p^{+}-\mathrm{Si}(100)$ при начальной плотности тока $200 \mathrm{MA} / \mathrm{cm}^{2}$. Видны входные отверстия (черные пятна) и множественные неразвившиеся зародыши пор (серые ямки).

зародышей пор при одновременном повышении термодинамической вероятности зарождения крупных пор. Следовательно, можно было бы ожидать резкого возрастания дисперсии пор по размерам. Однако в отличие от гомогенного зародышеобразования, когда способность к росту сохраняется у всех зародышей сверхкритического размера, вероятность прорастания пор в глубь кристалла может существенным образом зависеть от их размера. Для наиболее мелких пор фактором, препятствующим их развитию, может оказаться неполное отделение от кристалла полимерных цепочек, образующихся в последовательных циклах продвижения фронта реакции. Действительно, на полученных методами SEM и атомносиловой микроскопии изображениях пористых слоев кремния всегда обнаруживается множество мелких „затравочных“ ямок в пространстве между сформировавшимися порами (рис. 8). С другой стороны, частоты зарождения макроскопических пор должны быть всегда малы по сравнению с частотами зарождения нанопор уже в силу кооперативного характера самой химической реакции, требующей выполнения условий временно́й и пространственной когерентности. Кроме того, прохождение последующих циклов кооперативных реакций при продвижении фронта травления в глубь кристалла неизбежно ведет к появлению на месте крупных зародышей более мелких с термодинамически допустимыми размерами. При этом важнейшим фактором, определяющим преимущественный размер стационарных пор, становится тип и характер проводимости полупроводника, которые задают условия релаксации электронной подсистемы, следующей за каждым циклом инжекции электронов из зоны кооперативной реакции. Так, в кристаллах $p$-типа проводимости инжектируемые электроны должны полностью рекомбинировать с дырками в области, примыкающей к фронту продвижения пор. Раз- 
мер такой области и интенсивность происходящих в ней рекомбинационных процессов определяются концентрацией дырок в полупроводнике и интенсивностью потока электронов, т. е. плотностью анодного тока. Обусловленное рекомбинацией дополнительное энерговыделение вызывает повышение эффективной температуры в зоне реакции и приводит к увеличению масштаба флуктуаций, обеспечивающих воспроизведение кооперативных процессов нуклеофильной атаки. Поэтому стационарный размер пор, формирующихся в кристаллах $p$-типа проводимости, монотонно возрастает как с увеличением дырочной концентрации, так и с повышением плотности тока [3,20]. В кристаллах невырожденного кремния $n$-типа проводимости с относительно низким удельным сопротивлением $\left(n \sim 10^{17}-10^{18} \mathrm{~cm}^{-3}\right)$ аналогичные явления также присутствуют, поскольку порообразование происходит на фоне сильного изгиба зон и наличия инверсной области у границы раздела фаз. Однако в этом случае повышение уровня легирования кристалла ведет к сокращению размеров инверсного слоя и снижению эффективности рекомбинационных процессов. Соответственно с ростом электронной концентрации размер пор в слоях мезопористого кремния, образующихся при фиксированной плотности тока, должен уменьшаться, что и подтверждается экспериментальными данными $[3,20]$. В сильно легированных кристаллах $n^{+}-\mathrm{Si}$, приближающихся к порогу вырождения, рекомбинационные эффекты становятся несущественными, что предполагает еще меньший средний размер пор и более слабую его зависимость от концентрации свободных носителей заряда.

В отличие от кремния $p$-типа проводимости с достаточно высоким уровнем легирования, для которого энерговыделение на фронте порообразования является, вероятно, ведущим фактором, определяющим размер пор, для кристаллов $n$-Si влияние изменений плотности тока на этот параметр пористой структуры может оказаться неоднозначным. Поскольку повышение плотности тока, в общем случае способствующее увеличению размеров пор, обусловлено ростом скачка потенциала на межфазной границе, то в соответствии с рассмотренной выше моделью возникновения пор оно одновременно должно действовать и в сторону уменьшения их стационарного размера. С этим, в частности, можно связать наблюдаемый минимум на зависимости пористости слоев, формирующихся в $n$-кристаллах кремния, от плотности тока [26]. Показательна также наблюдавшаяся нами разница в размерах и структуре пор, появляющихся при экспозиции в концентрированной плавиковой кислоте пластин $n^{+}-\mathrm{Si}(100)$ в отсутствие и при наличии контакта их с металлом (см. рис. $1, a-e)$. В первом случае величина разности потенциалов между полупроводником и раствором $\mathrm{HF}$, появляющаяся при установлении в системе электрохимического равновесия, минимальна. Это исключает зарождение мелких пор и определяет распространение возникших макропор вдоль выделенных кристаллографических направлений $\langle 100\rangle$, поскольку это требует минимальной энергии активации. Когда же в установлении электрохимического равновесия участвует контактирующий с кремнием металл и разность потенциалов существенно возрастает, на тех же кристаллах формируются сплошные слои с неупорядоченной мезопористой структурой при размерах пор 10 нм.

В случае слабо легированных кристаллов кремния с достаточно высоким сопротивлением необходимое для начала химической реакции на межфазной границе падение потенциала достигается при напряжениях на ячейке, измеряемых десятками вольт. Основная часть этого напряжения падает в объеме самого полупроводника, создавая градиент потенциала, способный при начале электрохимического процесса приводить к лавинному пробою с выделением отдельных, пространственно изолированных каналов диссипации энергии. Такие каналы могут становиться областями локализации крупных макропор с микрометровыми размерами, распространяющихся перпендикулярно исходной поверхности, вдоль направления действия электрического поля. При этом на стенках макропор и на остающихся участках внешней поверхности сохраняется возможность формирования мезо- и микропористых слоев кремния.

\section{5. Заключение}

На основании результатов проведенных экспериментов по длительному темновому травлению в плавиковой кислоте сильно легированных кристаллов кремния $p$ - и $n$-типа проводимости в условиях повышенной температуры или же при наличии контакта с металлами, существенно различающимися величиной работы выхода электронов (Ag и $\mathrm{Pd})$, показано, что дырки валентной зоны не являются, как это принято считать, непосредственными и необходимыми участниками гетерогенной реакции кремния с анионами фтора в процессах электрохимического порообразования.

Сопоставление полученных зависимостей скоростей растворения кремния в HF в присутствии окислителей с различной величиной редокс-потенциала от типа и уровня легирования кристалла позволило установить, что инжекция дырок в валентную зону не является стадией, лимитирующей скорость травления кремния. При этом механизм травления (порообразование, сопровождающееся выделением продуктов неполного окисления кремния, или сплошное травление с непосредственным образованием $\mathrm{SiF}_{4}$ в гетерогенном процессе) и его скорость определяются величиной скачка потенциала, устанавливающегося на межфазной границе полупроводник-электролит.

Для объяснения процессов анодного порообразования в кремнии использована обоснованная ранее применительно к аналогичным процессам в полупроводниковых соединениях $\mathrm{A}^{\mathrm{III}} \mathrm{B}^{\mathrm{V}}$ модель самосогласованных кооперативных реакций нуклеофильного замещения между хемосорбированными анионами (адатомами фтора) и 
координационно-насыщенными атомами нижележащих слоев решетки кристалла, происходящих под действием падения потенциала на межфазной границе. Специфичность таких реакций, развивающихся на поверхности кремния, обусловлена наличием в атомах низко лежащих вакантных $d$-состояний, принимающих участие в формировании несвязывающих $d^{2} s p^{3}$-гибридных орбиталей, энергетическое положение которых соответствует акцепторным состояниям в области $\Delta$-долины зоны проводимости кристалла. В ходе реакции нуклеофильного замещения $d^{2} s p^{3}$-гибридные орбитали выступают в качестве электрофильных центров, обеспечивающих образование шестикоординированных переходных комплексов, включающих мигрирующие атомы фтора. Предлагаемая модель предполагает, что в результате прохождения каждого элементарного акта кооперативной реакции, протекающей на ограниченном участке поверхности кристалла, от него отделяются полимерные группировки атомов в виде цепочек $\left(\mathrm{SiF}_{2}\right)_{n}$. В ходе прорастания возникающих каналов пор в глубь кристалла такие первичные полимерные продукты заполняют их объем и выполняют функцию ионного проводника, обеспечивая селективную электродиффузию анионов фтора к фронту реакции на дне пор. Вытесняемые из пор эти продукты неполного окисления кремния взаимодействуют с молекулами $\mathrm{HF}$ и $\mathrm{H}_{2} \mathrm{O}$ электролита, выделяя водород. Кроме того, сохраняясь в объеме пор, эти же продукты способны к диспропорционированию, оставляя на их стенках мелкодисперсные частицы кремния.

Каждый элементарный акт кооперативной реакции нуклеофильного замещения сопровождается импульсной инжекцией электронов в зону проводимости кремния, что и обеспечивает протекание анодного тока. Особенности последующей релаксации электронной подсистемы кристалла, зависящие от типа и уровня его легирования, определяют размер прорастающих пор и структуру образующихся пористых слоев. В рамках используемых представлений находит непротиворечивое объяснение совокупность экспериментальных фактов, характеризующих анодные процессы, возникающие в ходе электрохимического и химического травления кремния в растворах HF:

- сам факт дискретного травления, приводящего к порообразованию;

- распространение пор в кристаллах кремния вдоль направлений семейства $\langle 100\rangle$;

- выделение водорода из области анодной реакции, в том числе и после завершения электрохимического процесса;

- отклонение эффективной валентности кремния при порообразовании от 2 и появление мелкодисперсных частиц кремния на стенках пор;

- возможность осцилляций анодного тока различной периодичности как следствие импульсного характера продвижения пор в решетке кристалла;

- смена режимов травления кремния при возрастании разности потенциалов между кристаллом и элек- тролитом с переходом от порообразования к сплошному растворению с непосредственным образованием полновалентных продуктов окисления;

- зависимости размеров пор от типа и уровня легирования исходного материала и величины анодного смещения (плотности анодного тока);

- формирование нанодисперсной кремниевой фазы при травлении кремния в HF-электролитах, содержащих умеренно сильные окислители.

Работа выполнена при частичной поддержке Российского фонда фундаментальных исследований (РФФИ) в рамках научного проекта № 16-29-01085. В работе использовалось оборудование центра коллективного пользования „Материаловедение и диагностика в передовых технологиях“. Особую признательность авторы выражают А.В. Нащекину и С.И. Павлову за получение SEM-изображений многочисленных образцов пористых структур.

\section{Список литературы}

[1] A. Volance. Phys. Rev. B, 55, 9706 (1997).

[2] M. Rausches, H. Spohn. Phys. Rev. E, 64, 031604 (2001).

[3] Xiaoge Gregory Zhang. Electrochemistry of Silicon and Its Oxide (N. Y., Boston-Dordrecht-London-Moscow, Kluwer Academic Publishers, 2004).

[4] V. Lehman, R. Stengl, A. Luigart. Mater. Sci. Engin. B, 69-70, 11 (2001).

[5] J. Carstensen, R. Prange, G.S. Popkirov, H. Foll. Appl. Phys. A, 67, 459 (1998).

[6] M.I.J. Beale, N.G. Chew, M.J. Uren, A.G. Cullis, J.D. Benjamin. Appl. Phys. Lett., 46 (1), 1095 (1985).

[7] O. Bisi, S. Ossicini, L. Pavesi. Surf. Sci. Rep., 38, 1 (2000).

[8] D.R. Turner. J. Electrochem. Soc., 107 (10), 810 (1960); D.R. Turner. J. Electrochem. Soc., 105 (7), 402 (1958).

[9] R. Memming, G. Schwandt. Surf. Sci., 4, 109 (1966).

[10] P. Allongue, V. Kieling, H. Gerischer. Electrochim. Acta, 40, 1353 (1995).

[11] K.W. Kolasinski. Phys. Chem. Chem. Phys., 5, 1270 (2003).

[12] K.W. Kolasinski. Surf. Sci., 603, 1904 (2009).

[13] K.W. Kolasinski, J.W. Gogola, W.B. Barclay. J. Phys. Chem. C, 116, 21472 (2012).

[14] В.П. Улин, С.Г. Конников. ФТП, 41 (7), 854 (2007).

[15] В.П. Улин, С.Г. Конников. ФТП, 41 (7), 867 (2007).

[16] Ю.Я. Гуревич, Ю.Я. Плесков. Фотоэлектрохимия полупроводников (М., Наука, 1983).

[17] Общая органическая химия. T. 6: Соединения селена, теллура, кремния и бора, под ред. Д. Бартона, У.Д. Оллиса (М., Химия, 1984).

[18] J.-M. Jancu, R. Scholz, F. Beltram, F. Bassani. Phys. Rev. B, 57 (11), 6493 (1998).

[19] G. Mariotto, F. Ziglio, F.L. Freire, jr., J. Non-Cryst. Sol., 192/193, 253 (1995).

[20] M.I.J. Beale, J.D. Benjamin, M.J. Uren, N.G. Chew, A.G. Cullis. J. Cryst. Growth, 73, 622 (1985).

[21] V. Lehmann, R. Stengl, A. Luigart. Mater. Sci. Engin. B, 69, 11 (2000).

[22] V. Lehmann, U. Gosele. Adv. Mater., 4, 114 (1992). 
[23] E.K. Propst, P.A. Kohl. J. Electrochem. Soc., 141, 1006 (1994).

[24] K.W. Kolasinski. Nanoscale Res. Lett., 9, 432 (2014).

[25] Г.В. Гадияк, Ю.Н. Мороков. ФТП, 27 (5), 736 (1993).

[26] A. Halimaoui. In: Properties of Porous Silicon, ed. by L.T. Canham (London, IEE INSPEC, The Institution of Electrical Engineers, 1997) p. 12.

Редактор Л.В. Шаронова

\title{
Anodic processes on Si crystals under chemical and electrochemical etching in acid fluorine solutions. Mechanism of pores formation
}

\author{
V.P. Ulin, N.V. Ulin, F.Yu. Soldatenkov
}

loffe Institute, 194021 St. Petersburg, Russia

Abstract Dark interaction of heavily doped Si crystals of $p$ - and $n$-type conductivity with $48 \% \mathrm{HF}$ water solution in the presence and without contact with having different work function metals (Ag and Pd) was studied. Dependences of dissolution rates of $\mathrm{Si}$ crystals in HF solutions which contain oxidizers with different redox potential values $\left(\mathrm{FeCl}_{3}, \mathrm{~V}_{2} \mathrm{O}_{5}\right.$ and $\left.\mathrm{CrO}_{3}\right)$ were investigated as a function of silicon doping type and level. Analysis of the obtained data allows to conclude that silicon valence band holes do not direct participate in anodic reactions of oxidation and dissolution of silicon atoms. In addition, the rate of silicon dissolution is not limited by the rate of hole generation. In contrast, we show that character and the rate of chemical processes leading to silicon dissolution in HF-containing electrolytes depended on the value of potential drop adjusted on the semiconductor-electrolyte interface. Mechanism of electrochemical pores formation in silicon crystals is discussed in the terms of self-consistent cooperative reactions of nucleophilic substitution between chemisorbed fluorine anions and silicon atoms of subsurface layer of the crystal. The specific feature of such reactions for silicon crystals consists in participation of nonbonding $d^{2} s p^{3}$-orbitales in formation of intermediate complexes. Energy levels of such orbitals are assumed to belong to $\Delta$-valley of conduction band of silicon crystals. In accordance with the proposed conception, the pore formation arise under potential drop in interface layer as a result of local separation from the crystal of $\left(\mathrm{SiF}_{2}\right) n$ polymer chains. The process leads to propagation of the pores mainly along $\langle 100\rangle$ crystal directions. Thermodynamic aspects of nucleation of the pores on the crystal surface and their sizes in the crystals of different type and doping levels are discussed. Basing on the model, noncontradictory interpretation of the existing experimental studies on the etching of silicon crystals in HF-containing solutions under different conditions can be suggested. 